\title{
A Time for Being Thankful: Balanced Time Perspective and Gratitude
}

\author{
Malgorzata Szczesniak, Celina Timoszyk-Tomczak \\ University of Szczecin \\ Szczecin, Poland
}

\begin{abstract}
The aim of this report is twofold: 1) to demonstrate how grateful disposition is related to time perspectives in late adolescents and young people in the process of transition into early adulthood; 2) to verify whether age indeed moderates the relationship between the present-hedonistic dimension and gratitude, as well as future and gratitude in such a way that these relationships are stronger in high school students and undergraduates than in graduates. The results provide strong support for the hypothesis that gratitude is higher in the case of the past-positive, present-hedonistic, and future time perspectives. As regards the reverse correlations, deviation from a balanced time perspective is positively associated with gratitude GQ-6 and IPIP-VIA. This suggests that different types of focus on recalling the past, experiencing the present, and facing the future might predict a grateful disposition and gratitude. Moreover, age moderated the relationship between the present-hedonistic perspective and gratitude.
\end{abstract}

Key words: gratitude, time perspectives, balanced time perspective, adolescents, young adults

\section{Introduction}

In recent years a large body of scientific evidence has emerged suggesting that being grateful is associated with several positive outcomes (Robustelli \& Whisman, 2018; Wood, Froh, \& Geraghty, 2010). Psychologists indicate that gratitude increases well-being in both younger (Jiang, Sun, Liu, \& Pan, 2016) and older individuals (Killen \& Macaskill, 2015). It correlates negatively with materialism (Polak \& McCullough, 2006) and positively with self-esteem (Kashdan, Uswatte, \& Julian, 2006; Kong, Ding, \& Zhao, 2015), social support, and life satisfaction (Kong, Ding, \& Zhao, 2015; Sun \&

Correspondence concerning this article should be addressed to Malgorzata Szczesniak, Ph.D., University of Szczecin, Faculty of Humanities, U1 Krakowska 71-79, 71-017 Szczecin, Poland. E-mail: malgorzata.szczesniak@whus.pl

Received October 27, 2017
Kong, 2013) on many levels of human life (Wang, Wang, \& Tudge, 2015). On the individual level, gratitude refers to experiencing and fostering appreciation of life and its events beneficial to the self. On the relational level, it concerns being grateful for bonds within family settings and friendships. On the organizational level, it relates to grateful relationships within the structural systems, among peers, employers, and employees.

Although there are a very large number of studies that explicitly investigate the topic of gratitude and its links with the aforesaid constructs, a systematic literature review shows that the subject of gratitude and time perspective has been one of the most understudied areas. And yet, if we think of human existence, gratitude represents an important factor of daily life stretched over time, across different developmental stages or mental and physical conditions. For example, for elderly people the awareness of the limited time they have left to live often promotes a sense of gratitude for life itself (Greenstein \& Holland, 2015). In fact, 
Carstensen (2011) explains this by pointing out that seniors' time horizons grow shorter as they move toward their later years and recognize the fragility of life. Consequently, they focus mainly on those goals from which they derive emotional meaning and tend to be more appreciative than younger adults (Chopik, Newton, Ryan, Kashdan, \& Jarden, 2017). Likewise, terminally ill patients are often grateful just for being alive, which manifests itself in wasting a smaller amount of time on irrelevant things and in enjoying every moment (Daughtery \& Hand, 2009). Middle-aged adults are grateful for the enjoyable circumstances experienced, together with the challenges and difficult lessons that allow them to grow (König \& Glück, 2014). Even adolescents seem to be attentive to gratitude and time perspective. As a matter of fact, almost 70\% of young Americans report expressing gratitude all the time (Wood, Froh, \& Geraghty, 2010), implying that their gratefulness is constantly present.

In this context, it seems valuable to undertake a study on the relationship between gratitude and time perspectives, especially in adolescents and younger adults, as the link between the two variables in these particular stages of life is important, though it may appear less evident.

\section{Gratitude}

Gratitude is considered an essential aspect of human existence and one of the most indispensable social emotions (Fox, Kaplan, Damasio, \& Damasio, 2015; Watkins, 2014). Current perspectives on gratitude provide insights into what gratitude is and how it can influence interpersonal relationships. Gratitude has been defined as a general tendency for people to recognize, appreciate, and respond to other individuals' benevolence and well-being (McCullough, Emmons, \& Tsang, 2002), as well as a passing emotion caused by particular situ- ations (Watkins \& Bell, 2017). According to Wood and colleagues (2010), gratitude can also be considered as part of a wider life orientation that consists in perceiving and valuing the positive in the world.

Another way of understanding gratitude is provided by Peterson and Seligman (2004), who argue that gratitude is a strength of character and a trait known in all cultures. In this sense, it is a disposition to be aware of and thankful for the good things that happen (Park, Peterson, \& Seligman, 2004). Moreover, it denotes a sense of thankfulness and enjoyment in response to obtaining a tangible benefit from another person or to receiving immaterial gifts - for example, in the form of natural beauty, such as awe-inspiring landscape or a work of art (Froh, Miller, \& Snyder, 2007; Peterson \& Seligman, 2004). Being grateful for what one has is regarded as appropriate, and acts of expressing thankfulness to those who have benefited us are usually considered socially desirable (Jackson, 2016).

Regardless of the conceptualization outlined above, being thankful requires subjective assessment of the gift received or the event experienced. If people consider what they have received or undergone beneficial, even if it involves suffering (König \& Glück, 2014), they are prompt to feel or show gratitude. By contrast, if they receive something valuable or meaningful but do not judge it accordingly, they remain thankless. Therefore, subjectivity may explain why some individuals are grateful even in hard times and why others feel entitled to more and persist in demanding more than others.

\section{Time Perspective}

Time is one of the most important dimensions of people's individual and social functioning (Lewin, 1946). Human life takes place in time; therefore, time - its role and meaning - is often the subject of psychological research. Time 
perspective (TP) is a category relating to subjective perception to the experience of time. Lewin (1942) described TP as a set of individual beliefs about the past and the future, emerging at a particular stage of human life. According to Nuttin (1985), time perspective, attitude toward time, and temporal orientation are the components of psychological time, where TP is the configuration of time-bound objects that occupy the mind of an individual in a particular situation.

TP can be defined as a relatively stable, individually diverse dimension, expressing an individual's preferred behaviors and attitudes toward the past, present, and future (Webster, 2011). One of the most influential theories of time perspective is the model proposed by Zimbardo and Boyd (2008), operationalized as an interesting research tool and tested by many researchers in the world. According to these psychologists, TP is a construct that includes personal, often unconscious, attitudes toward time. It is also a process that helps to bring order, consistency, and meaning tolife. Time perspective has three fundamental dimensions: past, present, and future (Zimbardo\& Boyd, 1999, 2008).

For a long time, research was focused primarily on a single time domain, for example, on the future (Holman \& Zimbardo, 2009; Nurmi, 1991). Recently, analytic emphasis has shifted to the role and function of balanced time perspective, which is believed to be related to mental and physical health, as well as to optimal individual and social functioning (Stolarski, Wiberg, \& Osin, 2015). Studies suggest that if people have a positive and balanced attitude toward the past, the present, and the future, they may benefit from higher well-being (Oyanadel, BuelaCasal, Araya, Olivares, \& Vega, 2014).

\section{Balanced Time Perspective}

Balanced time perspective (BTP) is understood as "the mental ability to switch effectively among TPs depending on task features, situational considerations, and personal resources, rather than be biased toward a specific TP that is not adaptive across situations" (Zimbardo \& Boyd, 1999, p. 1285). It can also be seen as a frequent and relatively balanced inclination to think positively about both the past and the future (Webster, 2011). Numerous contemporary studies have shown interesting relationships regarding balanced time perspective. BTP has been repeatedly found to correlate with subjective well-being (Boniwell, Osin, Linley, \& Ivanchenko, 2010; Drake, Ducan, Sutherland, Abernethy, \& Henry, 2008; Hang, Howell, \& Stolarski, 2013; Stolarski, 2016; Stolarski, Vowinckel, Jankowski, \& Zajenkowski, 2016) and various subjective indicators of well-being, such as subjective happiness, positive affect, negative affect, psychological needs, selfdetermination, and vitality. This relationship has been well-acknowledged even in circumstances of different BTP operationalization modes (Hang, Howell, \& Stolarski, 2013).

It has also been reported that higher BTP is associated with higher life satisfaction and general happiness (Barsics, Rebetez, Rochat, D'Argembeau, \& Van der Linden, 2017; Boniwell \& Zimbardo, 2004; Simons, Peeters, Janssens, Lataster, \& Jacobs, 2016; Webster \& Ma, 2013; Gao, 2011), extraversion (Stolarski, 2016; Zajenkowski, Witowska, Maciantowicz, \& Malesza, 2016), positive orientation (SobolKwapińska \& Jankowski, 2016), satisfaction with interpersonal relations (Stolarski, Wojtkowska, \& Kwiecińska, 2016), emotional intelligence(Stolarski, Bitner, \& Zimbardo, 2011), and mindfulness (Selma \& Sircova, 2013; Stolarski, Wojtkowska, \& Kwiecińska, 2016). Moreover, higher BTP is negatively correlated with pathophysiological stress (OliveraFigueroa, Juster, Morin-Major, Marin, \& Lupien, 2015). A more balanced profile of time perspective is related to fluid intelligence and higher executive control, which means that cognitive 
abilities play an important role in accepting time balance (Zajenkowski, Stolarski, Witowska, Maciantowicz, \& Łowicki, 2016). Time perspective may be important in acquiring skills (crystallized intelligence) and is also thought to influence the results of intelligence tests (Zajenkowski, Stolarski, Maciantowicz, Malesza, $\&$ Witowska, 2016). In addition, studies on the relationship between a balanced time perspective and psychological well-being in Chile showed the relativity of the BTP construct. According to researchers, BTP is age-related (Worrell, McKay, \& Andrett, 2015) and depends on the social and cultural context (Güell, Orchard, Yopo, \& Jamne-Molina, 2015). Webster and $\mathrm{Ma}$ (2013) report that, on average, younger adults are inclined to be future-oriented rather than past-oriented, while an average adult tends to be past- rather than future-oriented.

\section{Gratitude, Time, and Age}

Although the dimensions of time perspective and their balanced configuration can serve as predictors of numerous essential constituents of life, such as health, happiness, or financial and environmental commitments (Cunningham, Zhang, \& Howell, 2015), a systematic literature review does not yield a very large number of studies which explicitly investigate the topic of time perspective and its influence on dispositional gratitude.

Among the first researchers to look for such links were Emmons and McCullough (2003), who observed that approach to the past is crucial to the development of grateful attitudes, which allow people to appreciate their lives in the present. Similarly, Zimbardo and Boyd (2008) postulated a link between a past-positive perspective and dispositional gratitude. They argued that past-positive perspective could play a role in the development of dispositional gratitude. For example, an individual with a pastpositive temporal frame may draw on joyful memories associated with the kindness of others. In a more recent study, Watkins (2014) maintains that gratitude amplifies the good in positive memories and that grateful people are more focused on pleasant experiences, being more attentive to what they have than to what they lack. Moreover, Bhullar, Surman, and Schutte (2015) argue that both the past-positive temporal frame, which includes returning to or preserving positive memories of the past, and dispositional gratitude are associated with positive life outcomes such as life satisfaction and well-being. They demonstrate that higher levels of a past-positive temporal perspective are associated with greater gratitude and higher well-being.

Lake (2017) and Roberts (2014) point out that it is even possible to assume the existence of different forms of gratitude in human life. "Past gratitude" appears to be the most common form and consists in being thankful for the good things one has received from others at some point in life. It reflects the positive memories of any constructive or beneficial previous experiences. It relates to positive reminiscence and to recalling pleasant events from the past. According to some researchers (Martínez-Martí \& Ruch, 2014; Mehlsen, Platz, \& Fromholt, 2003; Palgi \& Shmotkin, 2010; Staudinger, Bluck, \& Herzberg, 2003), older people tend to focus on the past rather than on other dimensions of time. "Present gratitude" consists in being appreciative of pleasures experienced and gifts received in the "here and now" (Roberts, 2014). This kind of gratitude refers to a positive present event (Zimbardo \& Sword, 2017). The focus on the hedonistic present (i.e., presenthedonistic time perspective, $\mathrm{PH}$; Rosenbaum \& Ronen, 2013) seems to be characteristic of adolescents in particular. In fact, Zimbardo and Boyd (1999) claim that age is negatively correlated with $\mathrm{PH}$, which confirms that younger people concentrate on "living the moment" to a greater degree than their older counterparts. 
Finally, "future gratitude" implies being grateful for the life to come (Roberts, 2014). It is associated with the anticipation of being grateful for future positive experiences (Buck, 2004), as people are often inclined to hold an optimistic view of upcoming events and, consequently, anticipate positive rather than negative episodes (Wang, Gould, \& Hou, 2015). Similarly to $\mathrm{PH}$, future time perspective (FTP) is a typical characteristic of adolescents. Empirical research shows that higher chronological age is related to a more limited FTP (Brothers, Chui, \& Diehl, 2014; Weiss, Job, Mathias, Grah, \& Freund, 2016).

As regards empirical studies on gratitude and temporal perspective, Zhang, Howell, and Stolarski (2013) show that having a BTP is related to high gratitude. Specifically, they prove that individuals with past-positive, present-hedonistic, and future time perspectives report the highest levels of gratitude. By contrast, those with past-negative and present-fatalistic time perspectives report the lowest levels of subjective well-being. In regard to gratitude and future time perspective, Allemand and Hill (2014) assert that individuals who perceive their future time perspective (FTP) as open-ended report higher levels of gratitude in comparison to individuals who view their time as limited. Moreover, the FTP dimension appears to be positively associated with gratitude in the interpersonal domain. People who see their future as full of prospects declare higher levels of gratitude concerning social relationships. In contrast, people who tend to view their future in terms of time limitations, restraints, and boundaries are more grateful for the instrumental areas of life.

Although research on time perspective and gratitude seems clear, a review of the studies on the association between time perspectives and age (Mello \& Worrel, 2015) as well as between trait gratitude and age (Chopik, Newton, Ryan, Kashdan, \& Jarden, 2017; Froh, Kashdan,
Ozimkowski, \& Miller, 2009) is not free of inconsistencies and inconclusive findings (LaureiroMartinez, Trujillo, \& Unda, 2017). Some researchers suggest that young people focus more on the future and less on the past and the present (Mello \& Worrel, 2006). Other scholars observe that individuals give more attention to the present as they grow older (Zhang \& Ho, 2015). Still other research results support the hypothesis suggesting that people in general focus more on the past (Laureiro-Martinez, Trujillo, \& Unda, 2017). Similar discrepancies are found in studies on gratitude and age associations. To date, only a few reports have asserted the existence of a positive association between age and gratitude; research results demonstrate, however, that gratitude is higher in older adults than in younger ones (Chopik, Newton, Ryan, Kashdan, \& Jarden, 2017; Cosentino, 2014). On the other hand, there are scholars who found little or no associations between age and gratitude (Martínez-Martí \& Ruch, 2014; Sood \& Gupta, 2012).

In the light of these divergences, the present study is aimed at increasing the overall comprehension of the relationship between gratitude and time perspectives found in adolescents and early adults, including the moderating role of age. We postulate that age can affect the association of PH and FTP with gratitude understood as a disposition and with gratitude understood as a manifestation of character strength. The rationale behind this hypothesis is that during late adolescence and early adulthood young people, thanks to their cognitive development, acquire the ability to reflect on the past, the present, and the future (Blomgren, Svahn, Åström, \& Rönnlund, 2016). At the same time, although the two groups are very close to each other in terms of age, developmental changes are quite significant, as adolescents generally start their university studies and early adults usually begin their work and family life. What should also be underlined is that there 
are very few studies on the link between the above-mentioned variables (Allemand \& Hill, 2014; Chopik, Newton, Ryan, Kashdan, \& Jarden, 2017; Lang \& Carstensen, 2002), and research in this field is generally focused on specific time dimensions (past, present, or future) (Mello \& Worrel, 2015). Based on prior intervention research and on theoretical considerations mentioned above, we formulated the following hypotheses:

1) An increase in past-positive, present-hedonistic, and future dimensions of time perspective will increase gratitude understood as a disposition (GQ-6; McCullough, Emmons, \& Tsang, 2002) and as a character strength (IPIP-VIA; Goldberg et al., 2006). The time perspective variables listed will be positive predictors of gratitude.

2) A decrease in the levels of past-negative and present-fatalistic dimensions, which suggest a deviation from balanced time perspective, will increase gratitude understood as a disposition and as a character strength. The time perspective variables listed will be negative predictors of gratitude.

3) Age will moderate the relationship between the present-hedonistic dimension of time perspective and gratitude, as well as between future time perspective and gratitude. More specifically, the relationship will be moderated by age in such a way that the relationship will be stronger in high school students and in undergraduates than in graduates.

\section{Method}

\section{Participants and Procedure}

The sample consisted of 204 Polish students: high school students $(49.5 \%)$, undergraduates $(20 \%)$, and graduates $(30.5 \%)$. Their age ranged from 17 to $26(M=19.20, S D=2.026)$. The sample included an approximately equal number of women and men $(44.1 \%$ females, $54.4 \%$ males,
$1.5 \%$ did not report their gender). The respondents volunteered to participate in the study, were not rewarded for their participation, and completed a paper-and-pencil survey. Written parental consent was required from all participants under the age of eighteen.

\section{Measures}

In order to measure time perspectives and gratitude, we administered a set of questionnaires: the Zimbardo Time Perspective Inventory (ZTPI) by Zimbardo and Boyd (1999), Gratitude Questionnaire - Six Item Form (GQ-6) by McCullough, Emmons, and Tsang (2002), and the International Personality Item Pool - Values in Action (IPIP-VIA) by Goldberg and colleagues (2006).

The Zimbardo Time Perspective Inventory (ZTPI; Zimbardo \& Boyd, 1999), adapted into Polish by Cybis, Rowiñski, and Przepiórka (2012), consists of five scales corresponding to five time orientations: Past-Positive Time Perspective, which measures past events recollected in a positive and nostalgic way (e.g., "It gives me pleasure to think about my past"); Past-Negative Time Perspective, which reflects negative and aversive attitude to the past (e.g., "I think about the bad things that have happened to me in the past"); Present-Hedonistic Time Perspective, which captures pleasure derived from experiencing the "here and now," without considering the past or the future (e.g., "It is important to put excitement in my life"); Present-Fatalistic Time Perspective, which measures focus on the belief that all that happens in life is predetermined and that individual has no influence on their own fate (e.g., "My life path is controlled by forces I cannot influence"); and Future Time Perspective, which measures the respondent's focus on goals and future plans (e.g., "Meeting tomorrow's deadline and doing other necessary work comes before tonight's play"). Responses are rated on a five- 
point Likert scale, from very untrue (1) to very true (5).

Furthermore, we calculated deviation from balanced time perspective (DBTP) in order to determine how ill-balanced each participant was in this respect (Stolarski, Bitner, \& Zimbardo, 2011; Zajenkowski, Witowska, Maciantowicz, $\&$ Malesza, 2016). The formula that we used for this purpose is based on ZTPI scores and serves as an indicator of BTP (Zhang, Howell, \& Stolarski, 2013). From the mathematical point of view, DBTP is the root of the sum of squared deviations of a person's scores (i.e., $e P N$ ) from the optimal score on each scale (i.e., $o P N$ ) (Stolarski, Bitner, \& Zimbardo, 2011). This method is considered optimal among the existing methods of BTP assessment (Stolarski, Vowinckel, Jankowski, \& Zajenkowski, 2016). The formula is as follows:

$$
D B T P=\sqrt{(O P N-P P N)^{2}+(O P P-P P P)^{2}+(O P F-P P F)^{2}+(O P H-P P H)^{2}+(O F-P P)^{2}}
$$

An ideal score for each TP scale was adopted on the basis of optimal ZTPI raw scores (1.95 [oPN], 4.60 [oPP], 1.50 [oPF], $3.90[\mathrm{oPH}]$ and $4.00[\mathrm{oF}]$ ) (Zhang, Howell, \& Stolarski, 2013; Stolarski, Wiberg, \& Osin, 2015).

$$
\text { DDTP }=\sqrt{(1.95-3.42)^{2}+(4.60-3.13)^{2}+(1.50-2.42)^{2}+(3.90-3.96)^{2}+(4.00-3.10)^{2}}
$$

The lower (i.e., the closer to zero) the DBTP score, the higher the level of balanced time perspective (Zhang, Howell, \& Stolarski, 2013).

The Gratitude Questionnaire-6 (GQ-6; McCullough, Kilpatrick, Emmons, \& Larson, 2001; McCullough, Emmons, \& Tsang, 2002; Emmons, 2004) is a 6-item self-report assessment instrument measuring the experience of gratitude in everyday life (example items: "I have so much in life to be thankful for" or "As I get older I find myself more able to appreciate the people, events, and situations that have been part of my life history"). Participants respond to each item based on a 7-point Likert-type scale
(1 - strongly disagree; 7 - strongly agree). In this sample, the GQ-6 had satisfactory internal consistency (.75).

We also used elements of the International Personality Item Pool - Values in Action (IPIP-VIA) by Goldberg and colleagues (2006). The participants rated each gratitude item on a 5-point scale (1 - very much unlike me, 5 -very much like me). Examples of items are: "Express my thanks to those who care about me" (positive statement) or "Do not see the need to acknowledge others who are good to me" (reverse-coded). The gratitude dimension in our study had good internal consistency (.81).

\section{Results}

All the data collected from the above questionnaires were analyzed with the Statistical Package for Social Sciences (SPSS, Version 20). The descriptive statistics (means and standard deviations) for the time perspective dimensions, gratitude, age, and deviation from balanced time perspective are presented in Table 1. We also computed Pearson's $r$ correlations between these variables.

As in past research (Zhang, Howell, \& Stolarski, 2013), both GQ-6 and IPIP-VIA gratitude scores were positively related to past-positive, present-hedonistic, and future time perspectives. Contrary to what we had expected, however, there was no significant association between gratitude and the remaining dimensions of time perspective, namely past-negative and present-fatalistic. Moreover, as hypothesized, the results revealed that deviation from balanced time perspective correlated negatively with GQ-6 and IPIP-VIA gratitude.

To test if the positive correlates of time perspective could serve as positive predictors of gratitude understood as a disposition and a character strength, with negative correlates having a negative impact on them, we performed a stepwise linear progressive regression analy- 
sis (Table 2). The results indicate that the best predictor of GQ-6 gratitude is the past-positive dimension, which explains almost $10 \%$ of variance in the dependent variable, $\Delta R^{2}=.09, R=$ $.304, F_{(194,1)}=19.630, p=.001$. None of the remaining time perspective dimensions accounted for a significant proportion of variance in GQ-6 gratitude level (past-negative, $p=.599$; presenthedonistic, $p=.094$; present-fatalistic, $p=.066$; future, $p=.053$; and balanced time perspective, $p=.060)$. The results of the stepwise regression analysis suggest that GQ-6 gratitude may be higher in individuals who reinterpret their past in a positive manner.

The results also show that the best predictors of IPIP-VIA gratitude, which explain almost $20 \%$ of variance in the dependent variable $\left(\Delta R^{2}=.205, R=.467, F_{(185,3)}=16.879, p=.001\right)$, are the following dimensions of time perspective: past-positive, present-hedonistic, and fu- ture. The results of the stepwise regression analysis suggest that IPIP-VIA gratitude may be higher in individuals who have a sentimentally good view of past events, enjoy pleasures experienced "here and now," and strive for longterm goals (Zimbardo \& Boyd, 1999).

Finally, in order to check whether age was a moderator of the relationship between gratitude (dispositional and seen as a character strength) and time perspectives (present-hedonistic and future), we performed a moderation analysis with the PROCESS macro developed by Andrew F. Hayes (2018). Hypothesis 3 predicted that participants' age and hedonistic and future time perspectives would interact to affect gratitude, thus resulting in a more positive relationship between hedonistic/future perspectives and gratitude (dispositional gratitude and gratitude as a character strength) in high school students than in undergraduates and graduates.

Table 1 Means, standard deviations, and correlations between variables

\begin{tabular}{lcccccccccc}
\hline & $M$ & $S D$ & 1 & 2 & 3 & 4 & 5 & 6 & 7 & 8 \\
\hline 1. Past-positive & 3.13 & 0.90 & & & & & & & & \\
2. Past-negative & 3.42 & 1.08 & -.11 & & & & & & & \\
3. Present-hedonistic & 3.96 & 0.66 & $.35^{* *}$ & -.01 & & & & & & \\
4. Present-fatalistic & 2.42 & 0.87 & $.14^{*}$ & $.21^{* *}$ & .10 & & & & & \\
5. Future & 3.10 & 0.92 & $.15^{*}$ & .03 & .00 & .03 & & & & \\
6. GQ-6 gratitude & 5.08 & 1.05 & $.30^{* *}$ & -.06 & $.21^{* *}$ & -.08 & $.17^{*}$ & & & \\
7. IPIP-VIA gratitude & 3.66 & 0.69 & $.41^{* *}$ & .02 & $.31^{* *}$ & .02 & $.21^{* *}$ & $.72^{* *}$ & & \\
8. Age & 19.21 & 2.02 & .13 & -.04 & -.01 & -.01 & $.21^{* *}$ & $.19^{* *}$ & $.26^{* *}$ & \\
9. DBTP & 2.34 & 0.39 & $-.49^{* *}$ & $.64^{* *}$ & -.13 & $.39^{* *}$ & $-.42^{* *}$ & $-.26^{* *}$ & $-.22^{* *}$ & $-.14^{*}$ \\
\hline Note. ${ }^{*} p<.05,{ }^{* *} p<.01$ & & & & & & & & & &
\end{tabular}

Table 2 Results of stepwise linear regression for the dependent variables (Gratitude GQ-6, Gratitude IPIP-VIA) on independent variables - dimensions of time perspective $(N=204)$

\begin{tabular}{lccccc}
\hline Model & $B$ & $S E$ & $\beta$ & $t$ & $p$ \\
\hline $\begin{array}{l}\text { Gratitude GQ-6 } \\
\text { Past-positive }\end{array}$ & 0.359 & 0.081 & 0.304 & 4.431 & .001 \\
Gratitude IPIP-VIA & & & & & \\
$\quad$ Past-positive & 0.232 & 0.055 & 0.302 & 4.243 & .001 \\
Present-hedonistic & 0.207 & 0.072 & 0.202 & 2.865 & .005 \\
Future & 0.122 & 0.049 & 0.164 & 2.484 & .014 \\
\hline
\end{tabular}


The dependent variables in these equations were dispositional gratitude and gratitude considered as a character strength. We centered the main effects (e.g., Aiken \& West, 1991) in order to reduce multicollinearity between the main effects and the interaction term. As a result of a series of analyses, it became evident that age plays a moderating role only in the case of the relationship between the presenthedonistic perspective and a grateful disposition. The interaction factor is significant in the postulated model (Table 3), and a two-percent increase in the proportion of explained variance is also statistically significant, $\Delta R^{2}=.019$; $F_{(200,1)}=4.3, p=.039$. Although the small amount of explained variance might imply that the practical relevance of the interaction is marginal, McClelland and Judd (1993) observe that it is rather common for variance explained by interactions in field research to be small.

Table 4 presents the size of the effect of the present-hedonistic perspective in three age groups (high school students, undergraduates, and graduates). It appears that only in the groups of high school students and undergraduates is the impact of the present-hedonistic perspective on dispositional gratitude statistically significant. This influence disappears in the group of graduates, where it proves not to be statistically significant.

Age being a moderator, the strength of the relationship between present-hedonistic time perspective and dispositional gratitude differs across age groups. Figure 1 serves as an illustration of this relationship in the three age groups.

In the case of high school students and undergraduates there was a stronger relationship between the present-hedonistic perspective and dispositional gratitude than in the case of graduates (Figure 1).

\section{Discussion}

The purpose of this report is to explain whether time perspective dimensions and balanced time perspective are related to and predict gratitude understood as a disposition and

Table 3 Results of regression analysis with two predictors and an interaction factor

\begin{tabular}{lrrrrrr}
\hline & & & & & \multicolumn{2}{c}{$95 \%$ CI } \\
\cline { 5 - 7 } & \multicolumn{1}{c}{$B$} & $S E$ & $t$ & $p$ & \multicolumn{1}{c}{ LL } & UL \\
\hline Constant & 30.52 & 0.42 & 72.17 & .000 & 29.68 & 31.35 \\
Age & 0.64 & 0.21 & 3.00 & .003 & 0.22 & 1.06 \\
Present-hedonistic time perspective & 2.06 & 0.64 & 3.23 & .002 & 0.80 & 3.32 \\
$\begin{array}{l}\text { Age x Present-hedonistic time } \\
\text { perspective }\end{array}$ & -0.66 & 0.32 & -2.07 & .039 & -1.28 & -0.03 \\
\hline
\end{tabular}

Table 4 The effect of the present-hedonistic perspective in three age groups

\begin{tabular}{lcccccc} 
& & & & & \multicolumn{2}{c}{$95 \%$ CI } \\
\cline { 5 - 7 } & Effect & $S E$ & $t$ & $p$ & LL & UL \\
\hline High school students & 3.38 & 0.91 & 3.69 & $\mathbf{. 0 0 0}$ & 1.57 & 5.18 \\
Undergraduates & 2.06 & 0.64 & 3.23 & $\mathbf{. 0 0 2}$ & 0.80 & 3.32 \\
Graduates & 0.75 & 0.89 & 0.84 & .401 & -1.00 & 2.49 \\
\hline
\end{tabular}




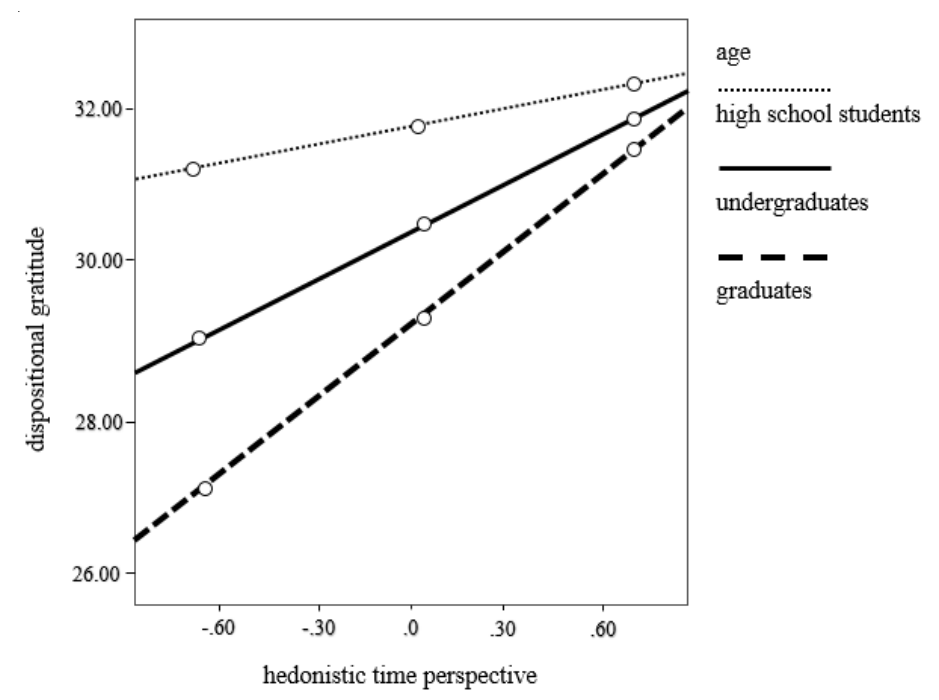

Figure 1 The effect of the present-hedonistic perspective on dispositional gratitude in three age groups.

gratitude understood as a character strength. The report is also meant to clarify the moderating role of age in the relationship between present-hedonistic perspective and gratitude as well as between future time perspective and gratitude.

The results provided above support the first hypothesis, postulating that gratitude is higher in the case of past-positive, present-hedonistic, and future time perspective dimensions. As regards the reverse correlations, the second hypothesis is only partially supported, and exclusively with respect to deviation from balanced time perspective, which was negatively associated with GQ-6 and IPIP-VIA gratitude. Additionally, our analysis has confirmed that age moderates the relationship between presenthedonistic perspective and gratitude. This pattern of outcomes is consistent with some of the previously obtained results (Zhang, Howell, \& Stolarski, 2013).
First of all, the past-positive time perspective dimension was positively correlated with and a predictor of gratitude. These findings are consistent with previous studies. Gratitude consists in "counting blessings" (Emmons \& McCullough, 2003) and is considered an individual's predisposition to appreciate the perceived benefits and the positive aspects of one's life (McCullough, Emmons, \& Tsang, 2002). Moreover, gratitude is conceptualized as retrospective appreciation and thankful response that follows favors received in the past (Hoy, Suldo, \& Mendez, 2013). In fact, other outcomes show that gratitude is related to a pervasive sense of abundance, which consists in recalling the benefits and pleasant life events that one has experienced and relished. People who believe that they are entitled to more favors than they have received are not likely to feel gratitude (Watkins, Grimm, \& Kolts, 2004). Other research results demonstrate that grate- 
ful individuals are likely to evoke subjective events from the past rather than objective ones to a greater extent than less grateful individuals (Watkins, Uhder, \& Pichinevskiy, 2015).

Secondly, the research done in the course of the present study additionally reveals an interesting interplay between the present-hedonistic dimension of time perspective and gratitude. The interaction effect between these two variables implies that people who tend to be grateful are distinguished by a focus on experiencing enjoyment and pleasure in the present. There are a few possible explanations for this link. In earlier studies (Holman \& Zimbardo, 2009), respondents who demonstrated higher present hedonism declared higher levels of social relationships and reported more assistance from friends and/or acquaintances. Therefore, a positive correlation between the present-hedonistic perspective and gratitude is understandable if one considers the latter as a social emotion (McCullough, Emmons, \& Tsang, 2002). Grateful individuals perceive benefits received thanks to other people's generosity, often reciprocate gifts and favors, and thus promote developing positive social ties (Fagley, 2016). At the same time, the results of our study can be perceived from yet another point of view. Over the years, researchers have consistently demonstrated that gratitude correlates positively with satisfaction, which reflects contentment with the quality of one's life (Hoy, Suldo, \& Mendez, 2013; Kong, Ding, \& Zhao, 2015). People with higher levels of gratitude have a propensity to perceive greater social support from others, which may contribute to an increase in their life satisfaction. An alternative explanation of the association between present-hedonistic perspective and gratitude refers to the mechanisms that have salutary effects on everyday functioning. Kashdan and colleagues (Kashdan, Uswatte, \& Julian, 2006) observed that in the Vietnam War veterans gratitude was positively related to daily hedonistic well-be- ing, also referred to as pleasure-attainment and pain-avoidance. Finally, present-hedonistic time perspective gives people energy and helps them enjoy simply being alive (Zimbardo \& Boyd, 2008), opening individuals to a sense of appreciation, which is closely related to gratitude (Watkins \& Bell, 2017).

Thirdly, we found that future time perspective was positively correlated with gratitude, although this outcome may seem surprising, as gratitude is generally associated with past and present time perspectives. Our findings, however, are consistent with an earlier study by Zhang, Howell, and Stolarski (2013), who reported the same kind of association. Moreover, Macaskill and Denovan (2014) observed that both gratitude and hope agency predicted life satisfaction. In the context of time perspective, gratitude and hope may connect the past and the future (Harvey \& Pauwels, 2004) and in the framework of conceptions developed by Peterson and Seligman (2004), overall well-being or psychological fulfillment can be attained by maintaining positive levels of emotions pertaining to the past (e.g., gratitude, forgiveness), present (e.g., satisfaction with life), and future (e.g., hope) (Hoy, Suldo, \& Mendez, 2013).

Another outcome concerns balanced time perspective and gratitude. Regardless of the lack of predicting value of DBTP on gratitude, we found that past-positive, present-hedonistic, and future dimensions of time perspective correlated positively with GQ-6 grateful disposition and IPIP-VIA gratitude, and that they were predictors of IPIP-VIA gratitude. Furthermore, the optimal BTP profile, measured with DBTP, was associated with both types of gratitude. These results allow us to cautiously conclude that the components of an optimally balanced time perspective (PP, PH, and F) blend and engage in triggering grateful situations. In this regard, Webster and Ma (2013) observed that discovering support, strength, and personal meaning by examining one's own past, as well 
as attaining a sense of happiness in the present and having a clear sense of future purpose, are associated with higher scores on well-being measures. Other studies confirm that expressing gratitude increases the sense of well-being (Boniwell \& Zimbardo, 2004; Watkins, 2014; Wood et al., 2005). On the basis of our research, one can safely state that people with BTP are capable of acting gratefully within a temporal mode suitable for the condition in which they find themselves at a particular moment of life. Thus, recollecting the past, experiencing the present, and facing the future may predict a grateful disposition and gratitude as a human strength.

Finally, in accordance with our assumptions, age proved to be a moderator in the association between present-hedonistic time perspective and dispositional gratitude: this association was stronger in both younger clusters than in graduates. Although there are no similar studies presenting analogous results, our outcomes are in line with some of the previous theoretical and empirical findings. Firstly, according to the developmental approach, adolescents attribute more importance to self-oriented values (hedonism, power, achievement) than adults (Schwartz, 2012) and exhibit a more evident present perspective (Siu, Lam, Le, \& Przepiórka, 2014). Focus on the "here and now" experience may help them to perceive the benefits of the present moment. In fact, Watkins (2014) maintains that grateful people, who are more focused on pleasant events, tend to be more attentive to what they currently have. This is related to research showing that a more pronounced present perspective at the expense of the future perspective is linked to lower ability to delay gratification (Wittmann, Rudolph, Linares Gutierrez, \& Winkler, 2015). Furthermore, individuals with a hedonistic orientation toward the present perceive their life as more purposeful (Sobol-Kwapiñska \& Jankowski, 2016). Such an attitude may also indicate their appreciative approach to life. On the other hand, graduates may focus less on the present-hedonistic perspective and assume a future time perspective as they finish their studies, enter the job market, and make critical decisions about family life. Even though graduates can be considered relatively young, they are emerging adults who start to display a different future perspective than they did a few years earlier, when they mainly concentrated on finishing their high school, passing their final exams, and starting their university education. In fact, some researchers (Creten, Lens, \& Simons, 2001; Siu, Lam, Le, \& Przepiórka, 2014) observe that many high school students live with a rather short future time perspective and are more present-oriented than adults, which makes it challenging for them to take the future into account in the "here and now." Ferrari, Nota, and Soresi (2010) came to a similar conclusion, proving that future orientation was stronger in older adolescents than in younger ones.

\section{Conclusions}

Our study has a number of significant strengths, one of them being its innovative character, given that there are not enough studies specifically focusing on the topic of time perspective as related to grateful disposition in adolescents and emerging adults. Yet, it is not free from significant limitations that need to be acknowledged and addressed. The first one is the use of self-report instruments, which are subject to social desirability bias. Nevertheless, self-report techniques remain an acceptable method of assessing time perspectives and gratitude. Another limitation stems from the fact that our study was cross-sectional; this kind of design makes it possible to measure group differences, but it reveals neither the direction of causal relationships between the variables nor patterns of individual change over time. As a result, we believe that future studies should 
examine the relationship between time perspectives, gratitude, and age using a longitudinal design tracking the determinants of growth and change on the personal level. Moreover, due to the fact that a large part of our study is correlational in nature, explaining the relationships we found in terms of cause and effect proves quite problematic. Therefore, another methodological recommendation would be to apply an experimental approach, which has the potential for investigating causation.

The results of our research may have some practical implications as well, especially as regards interventions promoting gratitude in high school students and undergraduates. It seems that being grateful at this stage of life is related to savoring pleasures in the present. Therefore, young people's capacity to appreciate and enjoy the present moment may help them to develop general thankfulness for simple events and for the things they experience daily. This kind of approach to the present has its advantages, as it supports confidence in oneself ("I am worthy of other people's attention and kindness") and others ("People around me are caring and benevolent"). The emotional cognition toward issues found good, valuable, and satisfactory may thus increase adolescents' active engagement in and responsibility for both today and tomorrow.

\section{References}

Allemand, M., \& Hill, P. L. (2014). Gratitude from early adulthood to old age. Journal of Personality, $84,21-35$.

Barsics, C., Rebetez, M. M. L., Rochat, L., D’Argembeau, A., \& Van der Linden, M. (2017). A French version of the Balanced Time Perspective Scale: Factor structure and relation to cognitive reappraisal. Canadian Journal of Behavioural Science / Revue Canadienne des Sciences du Comportement, 49, 51-57.

Bhullar, N., Surman, G., \& Schutte, N. S. (2015). Dispositional gratitude mediates the relationship between past-positive temporal frame and well-being. Personality and Individual Differences, 76, 52-55.
Blomgren, A. S., Svahn, K., Åström, E., \& Rönnlund, M. (2016). Coping strategies in late adolescence: Relationships to parental attachment and time perspective. The Journal of Genetic Psychology, 177(3), 85-96.

Boniwell, I., Osin, E., Linley, A. P., \& Ivanchenko, G. V. (2010). A question of balance: Time perspective and well-being in British and Russian samples. Journal of Positive Psychology, 5, 24-40.

Boniwell, I., \& Zimbardo, P. G. (2004). Balancing one's time perspective in pursuit of optimal functioning. In P. A. Linley \& S. Joseph (Eds.), Positive psychology in practice (pp. 165-180). Hoboken, NY, US: Wiley.

Brothers, A., Chui, H., \& Diehl, M. (2014). Measuring future time perspective across adulthood: Development and evaluation of a brief multidimensional questionnaire. The Gerontologist, 54, 1075-1988.

Buck, R. (2004). The gratitude of exchange and gratitude of caring: A developmental-interactionist perspective of moral emotion. In R. A. Emmons \& M. E. McCullough (Eds.), The psychology of gratitude (pp. 100-122). New York, NY, US: Oxford University Press.

Carstensen, L. L. (2006). The influence of a sense of time on human development. Science, 312, 19131915.

Chopik, W. J., Newton, N. J., Ryan, L. H., Kashdan, T. B., \& Jarden, A. J. (2017). Gratitude across the life span: Age differences and links to subjective wellbeing. The Journal of Positive Psychology, DOI: 10.1080/17439760.2017.141496.

Cosentino, A. C. (2014). Character strengths: Measurement and studies in Argentina with military and general population samples. In A. Castro Solano (Ed.), Positive psychology in Latin America: Cross-cultural advancements in positive psychology (pp. 111127). Dordrecht: Springer.

Creten, H., Lens, W., \& Simons, J. (2001). The role of perceived instrumentality in student motivation. In A. Efklides, J. Kuhl, \& R. M. Sorrentino (Eds.), Trends and prospects in motivation research (pp. 37-45). Dordrecht: Kluwer Academic Publishers.

Cunningham, K. F., Zhang, J. W., \& Howell, R. T. (2015). Time perspectives and subjective well-being: A dual-pathway framework. In M. Stolarski, N. Fieulaine, \& W. van Beek (Eds.), Time perspective theory; Review, research, and application: Essays in honor of Philip G. Zimbardo (pp. 403-415). New York, NY, US: Springer.

Cybis, N., Rowiński, T., \& Przepiórka, A. (2012). Development of the Polish version of Zimbardo Time Perspective Inventory. Poster presented at the $1^{\text {st }}$ International Conference on Time Perspective, Portugal, September 5-8, 2012. 
Daughtery, P. J., \& Hand, E. (2009). The unexpected gift: Inspirational stories of hope and significance. Bloomington, IN, US: iUniverse.

Drake, L., Ducan, E., Sutherland, F., Abernethy, C., \& Henry, C. (2008). Time perspective and correlates of wellbeing. Time \& Society, 17, 47-61.

Emmons, R. A. (2013). Gratitude works! A 21-day program for creating emotional prosperity. San Francisco, CA, US: Jossey-Boss.

Emmons, R. A., \& McCullough, M. E. (2003). Counting blessings versus burdens: An experimental investigation of gratitude and subjective well-being in daily life. Journal of Personality and Social Psychology, 84, 377-389.

Fagley, N. S. (2016). The construct of appreciation: It is so much more than gratitude. In D. Carr (Ed.), Perspectives on gratitude: An interdisciplinary approach (pp. 70-84). New York, NY, US: Routledge.

Ferrari, L., Nota, L., \& Soresi, S. (2010). Time perspective and indecision in young and older adolescents. British Journal of Guidance and Counselling, 38, 61-82.

Fox, G. R., Kaplan, J., Damasio, H., \& Damasio, A. (2015). Neural correlates of gratitude. Frontiers in Psychology, 6, 1-11. doi.org/10.3389/psyg.2015. 01491.

Froh, J. J., Kashdan, T. B., Ozimkowski, K. M., \& Miller, N. (2009). Who benefits the most from a gratitude intervention in children and adolescents? Examining positive affect as a moderator. The Journal of Positive Psychology, 4, 408-422.

Froh, J. J., Miller, D. N., \& Snyder, S. (2007). Gratitude in children and adolescents: Development, assessment, and school based intervention. School Psychology Forum, 2, 1-13.

Gao, Y. (2011). Time perspective and life satisfaction among young adults in Taiwan. Social Behavior and Personality: An International Journal, 39, 729-736.

Goldberg, L. R., Johnson, J. A., Eber, H. W., Hogan, R., Ashton, M. C., Cloninger, C. R., \& Gough, H. G. (2006). The international personality item pool and the future of public-domain personality measures. Journal of Research in Personality, 40, 84-96.

Greenstein, M., \& Holland, J. (2015). Lighter as we go: Virtues, character strengths, and aging. New York, NY, US: Oxford University Press.

Güell, P., Orchard, M., Yopo, M., \& Jamne-Molina, A. (2015). Time perspectives and subjective wellbeing in Chile. Social Indicators Research, 123, 127-141.

Harvey, J. H., \& Pauwels, B. G. (2004). Modesty, humility, character strength, and positive psychology. Journal of Social and Clinical Psychology, 23, 620623.

Hayes, A. F. (2018). Introduction to mediation, moderation, and conditional process analysis: A regres- sion-based approach. New York, NY, US: The Guilford Press.

Holman, E. A., \& Zimbardo, P. G. (2009). The social language of time: The time perspective-social network connection. Basic and Applied Social Psychology, 31, 136-147.

Hoy, B. D., Suldo, S. M., \& Mendez, L. R. (2013). Links between parents' and children's levels of gratitude, life satisfaction, and hope. Journal of Happiness Studies, 14, 1343-1361.

Jackson, L. (2016). Why should I be grateful? The morality of gratitude in context marked by injustice. Journal of Moral Education, 45, 276290.

Jiang, H., Sun, P., Liu, Y., \& Pan, M. (2016). Gratitude and late adolescents' school well-being: The mediating role of materialism. Social Indicators Research, 127, 1363-1376.

Kashdan, T. B., Uswatte, G., \& Julian, T. (2006). Gratitude and hedonic and eudaimonic well-being in Vietnam war veterans. Behaviour Research and Therapy, 44, 177-199.

Killen, A., \& Macaskill, A. (2015). Using a gratitude intervention to enhance well-being in older adults. Journal of Happiness Studies, 16, 947-964.

Kong, F., Ding, K., \& Zhao, J. (2015). The relationship among gratitude, self-esteem, social support and life satisfaction among undergraduate students. Journal of Happiness Studies, 16, 477-489.

König, S., \& Glück, J. (2014). "Gratitude is with me all the time": How gratitude relates to wisdom. Journals of Gerontology, Seiries B: Psychological Sciences and Social Sciences, 69, 655-666.

Lake, G. (2017). Getting free: Moving beyond negativity and limiting beliefs. Los Gatos, CA, US: Smashwords Edition.

Lang, F. R., \& Carstensen, L. L. (2002). Time counts: Future time perspective, goals and social relationships. Psychology and Aging, 17, 125-139.

Laureiro-Martinez, D., Trujillo, C., \& Unda, J. (2017). Time perspective and age: A review of age associated differences. Frontiers in Psychology, 8(101). https://doi.org/10.3389/fpsyg.2017.00101.

Lewin, K. (1942). Time perspective and morale. In G. Watson (Ed.), Civilian morale. Second yearbook of the S.P.S.S.L. (pp. 103-124). Boston, MA, US: Houghton Mifflin.

Lewin, K. (1946). Behavior and development as a function of total situation. In L. Carmichael (Ed.), Manual of child psychology (pp. 791-844). New York, NY, US: Wiley.

Macaskill, A., \& Denovan, A. (2014). Assessing psychological health: The contribution of psychological strengths. British Journal of Guidance \& Counselling, 42, 320-337. 
Martínez-Martí, M. L., \& Ruch, W. (2014). Character strengths and well-being across the life span: Data from a representative sample of German-speaking adults living in Switzerland. Frontiers in Psychology, 5, 1-10. doi: 10.3389/fpsyg.2014.01253.

McClelland, G. H., \& Judd, C. M. (1993). Statistical difficulties of defecting interactions and moderator effect. Psychological Bulletin, 114, 376-390.

McCullough, M. E., Emmons, R. A., \& Tsang, J. A. (2002). The grateful disposition: A conceptual and empirical topography. Journal of Personality and Social Psychology, 82, 112-127.

Mehlsen, M., Platz, M., \& Fromholt, P. (2003). Life satisfaction across the life course: Evaluations of the most and least satisfying decades of life. International Journal of Aging and Human Development, 57, 217-236.

Mello, Z. R., \& Worrell, F. C. (2006). The relationship of time perspective to age, gender, and academic achievement among academically talented adolescents. Journal for the Education of the Gifted, 29, 271-289.

Mello, Z. R., \& Worrell, F. C. (2015). The past, the present, and the future: A conceptual model of time perspective in adolescence. In M. Stolarski, N. Fieulaine, \& W. van Beek (Eds.), Time perspective theory: Review, research and application. Essays in honor of Philip G. Zimbardo (pp. 115-129). New York, NY, US: Springer.

Mroczek, D. K., \& Kolarz, C. M. (1998). The effect of age on positive and negative affect: A developmental perspective on happiness. Journal of Personality and Social Psychology, 75, 1333-1349.

Najderska, M., \& Cieciuch, J. (2013). Polska adaptacja kwestionariusza do pomiaru mocnych stron charakteru International Personality Item Pool Values in Action (IPIP-VIA): Wyniki wstępne [A Polish adaptation of the questionnaire for measuring character strengths, the International Personality Item Pool - Values in Action (IPIP-VIA): Preliminary results]. Studia Psychologica, 13, 65-83.

Nielsen, L., Knutson, B., \& Carstensen, L. L. (2008). Affect dynamics, affective forecasting, and aging. Emotion, 8, 318-330.

Nurmi, J. E. (1991). How do adolescents see their future? A review of the development of future - orientation and planning. Developmental Review, 11, 1-59.

Nuttin, J. (1985). Future time perspective and motivation. Leuven - Hillsdale: Leuven University Press Erlbaum

Olivera-Figueroa, L. A., Juster, R. P., Morin-Major, J. K., Marin, M. F., \& Lupien, S. J. (2015). A time to be stressed? Time perspectives and cortisol dynamics among healthy adults. Biological Psychology, 111, 90-99.
Oyanadel, C., Buela-Casal, G., Araya, T., Olivares, C., \& Vega, H. (2014). Percepción del tiempo: Resultados de una intervención grupal breve para el cambio del perfil temporal. Suma Psicológica, 21, 1-7.

Palgi, Y., \& Shmotkin, D. (2010). The predicament of time near the end of life: Time perspective trajectories of life satisfaction among the old-old. Aging and Mental Health, 14, 577-586.

Park, N., Peterson, C., \& Seligman, M. E. P. (2004). Strengths of character and well-being. Journal of Social and Clinical Psychology, 23, 603-619.

Peterson, C., \& Seligman, M. E. P. (2004). Character strengths and virtues: A handbook and classification. New York, NY, US: Oxford University Press.

Polak, E., \& McCullough, M. E. (2006). Is gratitude an alternative to materialism? Journal of Happiness Studies, 7, 343-360.

Roberts, R. (2014). God confidence: A practical guide for reaching the Divine zone. Bloomington, IN, US: Balboa Press.

Robustelli, B. L., \& Whisman, M. A. (2018). Gratitude and life satisfaction in the United States and Japan. Journal of Happiness Studies, 19, 41-55.

Rosenbaum, M., \& Ronen, T. (2013). Emotional wellbeing and self-control skills of children and adolescents: The Israeli perspective. In C. L. M. Keyes (Ed.), Mental well-being (pp. 209-229). Dordrecht: Springer.

Schwartz, S. H. (2012). Values and religion in adolescent development: Cross-national and comparative evidence. In G. Tromsdorff \& X. Chen (Eds.), Values, religion, and culture in adolescent development (pp. 97-122). Cambridge: Cambridge University Press.

Selma, R., \& Sircova, A. (2013). Mindfulness - A time perspective? Estonian study. Baltic Journal of Psychology, 14, 4-21.

Simons, M., Peeters, S., Janssens, M., Lataster, J., \& Jacobs, N. (2016). Does age make a difference? Age as moderator in the association between time perspective and happiness. Journal of Happiness Studies, 6, 1-11.

Siu, N. Y. F., Lam, H. H. Y., Le, J. Y. Y., \& Przepiórka, A. (2014). Time perception and time perspective differences between adolescents and adults. Acta Psychologica, 151, 222-229.

Sobol-Kwapińska, \& M., Jankowski, T. (2016). Positive time: Balanced time perspective and positive orientation. Journal of Happiness Studies, 17, 15111528.

Sood, S., \& Gupta, R. (2012). A study of gratitude and well-being among adolescents. Journal of Humanities and Social Science, 3, 35-38.

Staudinger, U. M., Bluck, S., \& Herzberg, P. Y. (2003). Looking back and looking ahead: Adult age differ- 
ences in consistency of diachronous ratings of subjective well-being. Psychology and Aging, 18, 1324.

Stolarski, M. (2016). Not restricted by their personality: Balanced time perspective moderates well-established relationships between personality traits and well-being. Personality and Individual Differences, 100, 140-144.

Stolarski, M., Bitner, J., \& Zimbardo, P. G. (2011). Time perspective, emotional intelligence and discounting of delayed awards. Time \& Society, 20, 346 363.

Stolarski, M., Matthews, G., Postek, S., Zimbardo, P. G., \& Bitner, J. (2014). How we feel is a matter of time: Relationships between time perspectives and mood. Journal of Happiness Studies, 15, 809-827.

Stolarski, M., Vowinckel, J., Jankowski, K. S., \& Zajenkowski, M. (2016). Mind the balance, be contented: Balanced time perspective mediates the relationship between mindfulness and life satisfaction. Personality and Individual Differences, 93, 27-31.

Stolarski, M., Wiberg, B., \& Osin, E. (2015). Assessing temporal harmony: The issue of a balanced time perspective. In M. Stolarski, N. Fieulaine, \& W. van Beek (Eds.), Time perspective theory: Review, research and application. Essays in honor of Philip G. Zimbardo (pp. 57-71). New York, NY, US: Springer.

Stolarski, M., Wojtkowska, K., \& Kwiecińska, M. (2016). Time for love: Partners' time perspectives predict relationship satisfaction in romantic heterosexual couples. Time \& Society, 25, 552-574.

Sun, P., \& Kong, F. (2013). Affective mediators of the influence of gratitude on life satisfaction in late adolescence. Social Indicators Research, 114, 13611369.

Wang, Q., Gould, T., \& Hou, Y. (2015). Is the future always brighter than the past? Anticipation of changes in the personal future after recall of past experiences. Memory, 23, 178-186.

Wang, D., Wang, Y. C., \& Tudge, J. R. H. (2015). Expressions of gratitude in children and adolescents: Insights from China and the United States. Journal of Cross-Cultural Psychology, 46, 1039-1058.

Watkins, P. C. (2014). Gratitude and the good life: Toward a psychology of appreciation. New York, NY, US: Springer.

Watkins, P. C., \& Bell, J. (2017). Current theories and research in the psychology of gratitude. In M. A Warren \& S. I. Donaldson (Eds.), Scientific advances in positive psychology (pp. 103-129). Santa Barbara, CA, US: Praeger.

Watkins, P. C., Grimm, D. L., \& Kolts, R. (2004). Counting your blessings: Positive memories among grateful persons. Current Psychology, 23, 52-67.
Watkins, P. C., Uhder, J., \& Pichinevskiy, S. (2015). Grateful recounting enhances subjective well-being: The importance of grateful processing. Journal of Positive Psychology, 2, 91-98.

Webster, J. D. (2011). A new measure of time perspective: Initial psychometric findings for the Balanced Time Perspective Scale (BTPS). Canadian Journal of Behavioural Science/Revue Canadienne des Sciences $d u$ Comportement, 43, 111-118.

Webster, J. D., \& Ma, X. (2013). A balanced time perspective in adulthood: Well-being and developmental effects. Canadian Journal of Aging, 32, 433442 .

Weiss, D., Job, V., Mathias, M., Grah, S., \& Freund, A. M. (2016). The end is (not) near: Aging, essentialism, and future time perspective. Developmental Psychology, 52, 996-1009.

Wittmann, M., Rudolph, T., Linares Gutierrez, D., \& Winkler, I. (2015). Time perspective and emotion regulation as predictors of age-related subjective passage of time. International Journal of Environmental Research and Public Health, 12, 16027 16042 .

Wood, A., Froh, J., \& Geraghty, A. (2010). Gratitude and well-being: A review and theoretical integration. Clinical Psychology Review, 30, 890-905.

Wood, S., Busemeyer, J., Koling, A., Cox, C. R., \& Davis, H. (2005). Older adults as adaptive decision makers: Evidence from Iowa gambling task. Psychology and Aging, 20, 230-225.

Worrell, F. C., McKay, M. T., \& Andrett, J. R. (2015). Concurrent validity of Zimbardo Time Perspective Inventory profiles: A secondary analysis of data from the United Kingdom. Journal of Adolescence, 42, 128-139.

Zajenkowski, M., Stolarski, M., Maciantowicz, O., Malesza, M., \& Witowska, J. (2016). Time to be smart: Uncovering a complex interplay between intelligence and time perspectives. Intelligence, 58 , $1-9$.

Zajenkowski, M., Stolarski, M., Witowska, J., Maciantowicz, O., \& Łowicki, P. (2016). Fluid intelligence as a mediator of the relationship between executive control and balanced time perspective. Frontiers in Psychology, 22, 1844. doi: 10.3389/ fpsyg.2016.01844.

Zajenkowski, M., Witowska, J., Maciantowicz, O., \& Malesza, M. (2016). Vulnerable past, grandiose present: The relationship between vulnerable and grandiose narcissism, time perspective and personality. Personality and Individual Differences, 98, 102-106.

Zhang, X., \& Ho, Y. W. (2015). In the pursuit of emotionally meaningful goals: When would the older East-Asians display or not to display the positivity 
effect? In S. T. Cheng, I. Chi, H. Fung, L. Li, \& J. Woo (Eds.), Successful aging (pp. 283-300). Dordrecht: Springer.

Zhang, J. W., Howell, R. T., \& Stolarski, M. (2013). Comparing three methods to measure a balanced time perspective: The relationship between a balanced time perspective and subjective well-being. Journal of Happiness Studies, 14, 169-184.

Zimbardo, P. G., \& Boyd, J. N. (1999). Putting time in perspective: A valid, reliable, individual-differences metric. Journal of Personality and Social Psychology, 77, 1271-1288.

Zimbardo, P. G., \& Boyd, J. N. (2008). The time paradox. The new psychology of time what will change your life. New York, NY, US: Free Press.

Zimbardo, P. G., \& Sword, R. K. M. (2017). Living and loving better with time perspective therapy: Healing from the past, embracing the present, creating an ideal future. Jefferson, NC, US: Exposit Books. 